\title{
A LÍNGUA MATERNA NO ENSINO MÉDIO: Finalidades e organização curricular
}

Maria Letícia Cautela de Almeida Machado ${ }^{(*)}$

\section{INTRODUÇÃO}

É senso comum - nos mais diversos países do mundo - o entendimento de que a língua materna constitui parte essencial da experiência curricular da educação básica, não apenas nos anos iniciais do ensino fundamental - período oficialmente associado ao processo educacional de alfabetização -, como também nos anos subsequentes do nível fundamental e médio. Nas últimas décadas, tem-se acompanhado, no Brasil, um número crescente de pesquisas, bem como de proposições e execuções de políticas públicas educacionais, voltadas para a alfabetização de crianças, jovens e adultos, no entanto, ainda é assistemática a discussão acerca da natureza formativa do ensino de língua materna na educação de nível médio.

Tradicionalmente, o ensino de língua materna tem assumido, no ensino médio, uma perspectiva estritamente gramatical normativa e filológica, privilegiando o estudo dos fatos de gramática da língua padrão, sempre tomados desde si mesmos, como conteúdos curriculares. Mais recentemente - a partir da incorporação de estudos advindos da Sociolinguística, da Psicolinguística, da Pragmática, da Análise do Discurso e da Linguística Textual-, deslocou-se a ênfase para as práticas de leitura de mundo e a expressividade. Embora não se possa negar os avanços decorrentes de tais estudos, ocorreram alguns equívocos na transposição dessas teorias para a prática de sala de aula, entre os quais - o mais preocupante - o entendimento de que os fatos gramaticais do sistema da língua poderiam ser relegados a segundo plano - ou até omitidos - no programa curricular do estudo da língua materna no ensino médio.

É fato que o escopo curricular do ensino de língua materna nos três anos do ensino médio deve possibilitar, a esses jovens de 14 a 18 anos, a interação com uma variedade de gêneros discursivos e textos, não apenas literários, mas também científicos, técnicos e administrativos, essenciais para a efetiva inserção social e profissional. No entanto, é preciso considerar que para o uso efetivo de tais gêneros é essencial o domínio do sistema formal da língua escrita, se não para sua produção, para sua adequada leitura e fruição.

\footnotetext{
${ }^{(*)}$ Professora adjunta da Faculdade de Educação da UERJ. Departamento de Estudos Aplicados ao Ensino. Área de Linguística Aplicada à Alfabetização e ao Letramento. Atuação na Pós-graduação em Psicopedagogia do Instituto de Psicologia da UERJ. E-mail: maria leticia2005@hotmail.com.
} 
Nesse contexto, este artigo tem por objetivo problematizar as finalidades e a organização curricular do ensino de língua materna no ensino médio, com vistas a contribuir para um projeto consistente de formação de leitores e produtores de texto. O maior desafio é sobrepujar a ideia equivocada de que o ensino dos fatos gramaticais da língua materna e o ensino de produção e leitura textuais possam ser arrolados como experiências curriculares distintas e desconexas umas das outras.

\section{A LINGUAGEM, A LÍNGUA E OS GÊNEROS DO DISCURSO}

A linguagem é um fenômeno complexo que envolve mais do que a capacidade humana de construir e empregar sistemas simbólicos não verbais e verbais. A linguagem é, ao mesmo tempo, uma atividade cognitiva, comunicativa e interativa, sendo a língua um de seus instrumentos. A linguagem é uma atividade cognitiva de ação sobre o mundo, porque através dela o sujeito estrutura a realidade e organiza o pensamento: planeja ações, refleti, significa e ressignifica, constrói conceitos, enfim, representa e ajuíza o mundo (MACHADO, 2013).

Em decorrência disso, a linguagem assume um papel na construção do próprio conhecimento, pelo fato de ela, ao mesmo tempo, integrar os processos cognitivos/mentais e mediar tais processos com o mundo social.

Deste modo, a linguagem é, também, atividade comunicativa a partir da qual os sujeitos comunicam o que tem a dizer a alguém e, assim, estabelecem laços interativos com os outros. A linguagem é, pois, constitutiva dos sujeitos e das relações sociais. Ela é um fato histórico-social, que se desenvolve nas práticas sociais impregnadas de valor cultural. Nessas práticas sociais as diferentes culturas influenciam os sujeitos, seus modos de ver e de representar o mundo.

Por conseguinte, é por meio da linguagem que o ser humano age, criando e recriando um mundo que não é só fruto de projeções e representações individualizadas por meio da língua, mas resultado de práticas sociointerativas. Daí afirmar-se que a língua é uma atividade constitutiva e criativa, que implica ação conjunta dos sujeitos em determinada situação concreta de interação (CARVALHO; MENDONÇA, 2006).

Nesse contexto, a língua é vista de forma integrada e dinâmica, um sistema simbólico constituído por signos linguísticos cuja existência funda-se nas necessidades reais de interação social. Trata-se, portanto, de um fato social, histórico, desenvolvido de acordo com as práticas sociais e, como tal, obedecendo a convenções de uso. 
Nas interações, códigos - símbolos que estão em uso e permitem a adequação de sentidos partilhados - são gerados e transformados e representações são convencionadas e padronizadas. Os códigos se mostram em conjunto de escolhas e combinações discursivas, gramaticais, lexicais, fonológicas, gráficas, etc. (BRASIL, 2000a).

Portanto, o ato interlocutivo pressupõe uma competência social de utilizar a língua, ou demais códigos, de acordo com as expectativas em jogo. As condições e formas de comunicação refletem a realização social em símbolos que ultrapassam as particularidades do sujeito, que passa a ser visto em interação com o outro.

A partir desta perspectiva interacional, entende-se, ainda, que a língua se concretiza em enunciados (orais e escritos), na atividade dialógica, no terreno interindividual. O enunciado, na verdade, explica Bakhtin (1997), não é uma unidade convencional da língua - como a oração -, mas uma unidade real da comunicação verbal, estritamente delimitada pela alternância dos locutores, e que termina por uma transferência da palavra ao outro. No entanto, o enunciado é constituído com a ajuda de unidades da língua: uma palavra, um conjunto de palavras ou um conjunto de orações.

Essas unidades da língua se convertem em enunciados ao possibilitar, na interação verbal, uma atitude responsiva ativa para com elas. De tal modo que todo enunciado é prenhe de resposta e, de uma forma ou de outra, forçadamente a produz: o ouvinte torna-se o locutor. Conforme Bakhtin (1997), cedo ou tarde, o que foi ouvido e compreendido de modo ativo encontrará um eco no discurso ou no comportamento subsequente do ouvinte. O locutor postula essa compreensão responsiva ativa: o que ele espera não é uma compreensão passiva, mas uma resposta, uma concordância, uma objeção, uma execução. De tal maneira que todo enunciado se elaborada como que para ir ao encontro dessa resposta:

Enquanto elaboro meu enunciado, tendo a determinar essa resposta de modo ativo; por outro lado, tendo a presumi-la, e essa resposta presumida, por sua vez, influi no meu enunciado (precavenho-me das objeções que estou prevendo, assinalo restrições, etc.). Enquanto falo, sempre levo em conta o fundo aperceptivo sobre o qual minha fala será recebida pelo destinatário: o grau de informação que ele tem da situação, seus conhecimentos especializados na área de determinada comunicação cultural, suas opiniões e convicções, seus preconceitos (de meu ponto de vista), [...], etc.; pois é isso que condicionará sua compreensão responsiva de meu enunciado. Esses fatores determinarão a escolha do gênero do enunciado, a escolha dos procedimentos composicionais e, por fim, a escolha dos recursos linguísticos, ou seja, o estilo do meu enunciado [...] (BAKHTIN, 1997, p. 321).

Assim, todo enunciado é elaborado tendo em conta o interlocutor. Esse outro influencia sobremaneira na composição do enunciado, sobretudo em seu estilo. 
De acordo com Bakhtin (1997), cada esfera de utilização da língua, conforme a especificidade da comunicação verbal, elabora seus tipos relativamente estáveis e normativos de enunciados - os quais são denominados gêneros do discurso. A riqueza e a variedade dos gêneros são infinitas, uma vez que as possibilidades de ação humana são inesgotáveis e cada esfera de ação humana comporta um repertório significativo de gêneros do discurso.

Assim, os gêneros estabelecem uma interconexão da linguagem com a vida social, abarcando a totalidade dos usos da linguagem, sendo divididos, conforme Bakhtin (1997), em primários e secundários. Os primários se constituem em circunstâncias de comunicação verbal cotidiana espontânea e, sobretudo, oral, mas podem incluir também alguns tipos de escrita informal e de circulação privada. Estes gêneros tendem a ser empiricamente mais interativos, mantendo uma relação imediata com a realidade existente. Já os gêneros secundários se constituem em circunstâncias de uma comunicação cultural mais complexa, principalmente escrita: artística, científica, pedagógica, jornalística, jurídica, religiosa, política, filosófica, etc.; tendendo a ser mais monologizados.

Deste modo, os gêneros permeiam nossa vida diária e organizam nossa comunicação. Em toda atividade humana, valemo-nos de vários gêneros - orais ou escritos, impressos ou digitais utilizados socialmente e típicos de nossa sociedade letrada urbana (ROJO; BARBOSA, 2015). A matéria dos gêneros, sejam primários ou secundários, é a mesma: enunciados verbais, fenômenos da mesma natureza, diferenciados pelo grau de complexidade e elaboração em que se apresentam.

Para Bakhtin (1997), os gêneros do discurso apresentam três dimensões essenciais e indissociáveis que compõem o todo que constitui o enunciado, que é marcado pela especificidade de uma esfera de ação: o conteúdo temático, que diz respeito ao domínio de sentido de que se ocupa um gênero; a construção composicional, que se refere à sua estrutura formal propriamente dita e o ato estilístico, que alude à seleção de recursos lexicais, fraseológicos e gramaticais disponibilizados pela língua, vinculada a unidades temáticas e composicionais determinadas. Tal seleção é também realizada em função da imagem do interlocutor e de como se presume sua compreensão responsiva ativa do enunciado, pois, como sinalizado acima, logo de início o locutor espera dele uma resposta.

Todas estas três dimensões dos gêneros discursivos são determinadas pelos parâmetros do contexto de uso ou da situação de produção dos enunciados. Tal contexto ou situação envolve alguns elementos, tais como: - quem são os parceiros da interlocução, ou seja, quem fala/escreve e para quem; - quais os lugares sociais dos interlocutores e seus posicionamentos ideológicos; - em que situação, lugar e momento histórico se situa; - em que veículo ou tipo de mídia será difundido; 
- com que objetivo, finalidade ou intenção; - em que língua; - em que esfera da comunicação (BARBOSA, 2001).

Além disso, os gêneros unem estabilidade e instabilidade, permanência e mudança. De um lado, reconhecem-se propriedades comuns em conjuntos de textos; de outro, essas propriedades alteram-se continuamente. Isso ocorre porque as atividades humanas não são nem totalmente determinadas nem aleatórias. Assim, os gêneros estão em contínua mudança. À medida que as esferas de atividade se desenvolvem e ficam mais complexas, gêneros desaparecem ou aparecem, gêneros diferenciam-se, gêneros ganham um novo sentido. Isso implica que é preciso considerar a historicidade dos gêneros (FIORIN, 2008).

Os gêneros discursivos, cada vez mais flexíveis no mundo contemporâneo, marcam, portanto, a natureza social da língua. Assim, os gêneros somente ganham sentido quando se percebe a correlação entre formas, atividades e contextos. A funcionalidade dos discursos determina o como e o que dizer ou escrever. Assim, a falta de domínio do gênero é a falta de vivência de determinadas atividades de certa esfera de comunicação. Fala-se e escreve-se sempre por gêneros e, portanto, aprender a falar e a escrever é, antes de mais nada, aprender gêneros.

Esse entendimento se integra à concepção dos processos de oralidade e escrita como práticas sociais e históricas atualizadas no uso efetivo das línguas oral e escrita. Estas entendidas, conforme Senna (2011), enquanto sistemas linguísticos que se distinguem, não apenas em seus aspectos estritamente gramaticais, mas especialmente por suas condições de produção, tanto mentais como sociais.

Oralidade e escrita são, pois, práticas específicas, mas, ao mesmo tempo, interativas nas sociedades atuais e não devem ser tomadas como estanques e isoladas. Trata-se, conforme Carvalho e Mendonça (2006), de processos que não são neutros, enquanto condições discursivas das formas de produção e expressão de conhecimento, e nem há entre eles uma supremacia em termos cognitivos, pois são modos de representação cognitiva e social que se revelam em práticas específicas.

O exposto evidencia, portanto, que compreender e usar a língua portuguesa como língua materna é um processo que exige competências complexas cognitivas, linguísticas, comunicativas e sociais. O uso da língua só pode ser social e o social, longe de ser linear, leva a intricadas redes de relações, sentidos e significações. 


\section{O ENSINO DA LÍNGUA MATERNA NO ENSINO MÉDIO}

A antiga reformulação do ensino médio no Brasil, estabelecida pela Lei de Diretrizes e Bases da Educação Nacional de 1996, regulamentada em 1998 pelas Diretrizes do Conselho Nacional de Educação e pelos Parâmetros Curriculares Nacionais - PCNEM-, já buscava atender a uma reconhecida necessidade de atualização da educação brasileira. Atualização necessária tanto para impulsionar uma democratização social e cultural mais efetiva, pela ampliação da parcela de jovens que completam a educação básica, como para responder a desafios impostos por processos globais, que têm excluído da vida econômica os trabalhadores não-qualificados, por conta da formação exigida pelo sistema de produção e de serviços (BRASIL, 2000b).

Tal reformulação definiu o ensino médio como a etapa conclusiva da educação básica de toda a população estudantil, deixando de ser apenas um período preparatório para o Ensino Superior ou estritamente profissionalizante. Isso significou o entendimento de que tal ensino, em qualquer de suas modalidades, deveria preparar para a vida, qualificar para a cidadania e para o aprendizado permanente, seja no eventual prosseguimento dos estudos, seja no mundo do trabalho.

Num mundo contemporâneo, de tão rápidas transformações e de tantas contradições, estar formado para a vida real significa mais do que reproduzir dados, denominar classificações ou identificar símbolos. Significa ser capaz de comunicar e argumentar; compreender e solucionar problemas; participar de um convívio social como cidadão; fazer escolhas e proposições e, especialmente, assumir uma atitude de permanente aprendizado. Nesse contexto, a língua materna ocupa papel central.

Assim sendo, o ensino de língua materna, na atualidade, requer como finalidades desenvolver no aluno seu potencial crítico, sua percepção das múltiplas possibilidades de expressão linguística, sua formação como escritor e leitor efetivo dos mais diversos textos representativos de nossa cultura. Os PCNEM (BRASIL, 2000b) sinalizam que, para além da memorização mecânica de regras gramaticais, o aluno deve ter meios para ampliar e articular conhecimentos e competências que possam ser mobilizados nas inúmeras situações de uso da língua com que se depara, na família, entre amigos, na escola, no mundo do trabalho. Desse modo, o ensino da língua materna não visa apenas ao domínio técnico, mas principalmente à competência ${ }^{1}$ de desempenho, ao saber usar as linguagens em diferentes situações ou contextos.

\footnotetext{
${ }^{1}$ Competência é definida nos PCNEM (BRASIL, 2000b), nos termos de Perrenoud, como "a faculdade de mobilizar um conjunto de recursos cognitivos (saberes, capacidades, informações etc.) para solucionar com pertinência e eficácia uma série de situações” (p. 30).
} 
O desenvolvimento da competência linguística do aluno no ensino médio, dentro dessa perspectiva, não está pautado na exclusividade do domínio técnico de uso da língua legitimada pela norma padrão, mas, principalmente, no saber utilizar a língua, em situações subjetivas e/ou objetivas que exijam graus de distanciamento e reflexão sobre contextos e estatutos de interlocutores [...] (BRASIL, 2000a, p.11).

Deste modo, os PCNEM já apontavam, há quase duas décadas, para uma mudança e inovação no ensino da língua materna no ensino médio: de uma perspectiva centrada na tradição gramatical normativa e filológica para uma perspectiva centrada na competência comunicativa do aluno, uma concepção profundamente humanista e social do ensino. Todavia, tal entendimento ainda está longe de suceder-se na realidade escolar.

É imprescindível que o processo de ensino da língua materna se paute em propostas interativas de linguagem, considerada em um processo discursivo de construção do pensamento simbólico, constitutivo de cada aluno em particular e da sociedade em geral. Essa concepção de ensino destaca a natureza social e interativa da linguagem, em contraposição às concepções tradicionais deslocadas do uso social.

Desse modo, os conteúdos tradicionais (como a literatura, a gramática, a produção do texto escrito e as normas) precisam ser incorporados por uma perspectiva maior, que é a linguagem, entendida como um espaço dialógico. Nesse sentido, todo o conteúdo tem seu espaço no estudo da língua materna, desde que possa colaborar para a objetivação das competências em questão.

O estudo da gramática passa a ser uma estratégia para compreensão, interpretação e produção de textos. No entanto, sistematicamente, as práticas escolares são planejadas sob a forma de orações que não comunicam. Há estereótipos educacionais complexos e difíceis de serem rompidos, como no caso do ensino das classificações apriorísticas de termos gramaticais. Não se trata de negar a necessidade de ensiná-los, a questão está em como ensiná-los, em razão do ato comunicativo. Como assinalam os PCNEM (2000a), a gramática extrapola em muito o conjunto de orações deslocadas do texto.

Assim sendo, o estudo da gramática em contextos comunicativos deve ser pauta da organização curricular do ensino da língua materna. É necessário ponderar sobre a adequação da linguagem a situações de uso, uma vez que de nada adianta os alunos saberem responder uma série de exercícios descontextualizados de gramática e não dominarem o uso desse conhecimento gramatical na compreensão e produção de textos.

Deste modo, a unidade básica do ensino da língua materna no ensino médio é o texto, 
[...] compreendido como a fala e o discurso que se produz, e a função comunicativa, o principal eixo de sua atualização e a razão do ato linguístico. [...] O texto só existe na sociedade e é produto de uma história social e cultural, único em cada contexto, porque marca o diálogo entre os interlocutores que o produzem e entre os outros textos que o compõem. (BRASIL, 2000a, p.18).

O texto, portanto, não consiste no somatório de palavras e frases; sua existência é marcada por um fluxo contínuo, dinâmico, identificável nos espaços interativos relacionados à vida social (SILVA, 2013). Rojo e Barbosa (2015) complementam tal entendimento ao afirmarem que um texto ou enunciado é um dito (ou cantado, ou escrito, ou mesmo pensado) concreto e único, irrepetível, que gera significação e se vale da língua para sua materialização, constituindo o discurso. Desse modo, todo texto se organiza dentro de um determinado gênero discursivo.

Vale lembrar que os gêneros não são entidades naturais, mas artefatos culturais construídos historicamente pelo ser humano (MARCUSCHI, 2010). Assim sendo, as práticas de ensino da língua materna devem envolver práticas sociais de uso da linguagem. Rojo (2006) sinaliza que essas práticas de linguagem remetem a:

[...] uma noção de ordem social, que implica a inserção dos interlocutores em determinados contextos ou situações de produção, a partir dos quais, tendo a linguagem como mediadora, os agentes sociais estabelecem diferentes tipos de interação e de interlocução comunicativa, visando diferentes finalidades de comunicação, a partir de diversificados lugares enunciativos (ROJO, 2006, p. 25).

Segundo a autora, está claro que esses sujeitos sociais dependem de suas experiências de vida, de seu conhecimento acumulado a respeito de tais práticas, para poderem enunciar. Nessa perspectiva, a aprendizagem é sempre um processo de apropriação das experiências acumuladas pela sociedade no curso de sua história.

Visto assim é que os PCNEM (BRASIL, 2000a) enfocam o ensino da língua materna como um processo de continuidade da apropriação de práticas sociais em circulação em espaços públicos e formais. E estas práticas sociais circulam na forma de textos orais ou escritos.

Isto posto, para além de abordar o texto em suas propriedades formais e estilísticas particulares, a organização curricular do ensino da língua materna no ensino médio requer bases firmadas em uma concepção de texto inserido em um discurso, ou seja, o texto como um evento integrado a uma situação dialógica em que se manifestam elementos linguísticos e extralinguísticos, de acordo com as diversas situações comunicativas, relacionadas aos diversos gêneros discursivos.

Deste modo, conforme sinalizam os PCNEM, 
Toda e qualquer análise gramatical, estilística, textual deve considerar a dimensão dialógica da linguagem como ponto de partida. O contexto, os interlocutores, gêneros discursivos, recursos utilizados pelos interlocutores para afirmar o dito/escrito, os significados sociais, a função social, os valores e o ponto de vista determinam formas de dizer/escrever [...] (BRASIL, 2000a, p. 21).

Assim, diferentemente de posições gramaticais ou estruturais, os gêneros e os textos a eles pertencentes não podem ser conhecidos, compreendidos ou produzidos sem referência aos elementos de sua situação de produção. O que implica reiterar que se se pretende formar sujeitos sociais da comunicação, é preciso trabalhar com os alunos os quatro elementos que compõem os gêneros: conteúdo temático, construção composicional, estilo verbal e situação de produção.

Essa perspectiva de organização curricular do ensino da língua materna permite: capturar, para além dos aspectos estruturais presentes em um texto, também aspectos sócio históricos e culturais; concretizar a que forma de dizer em circulação social estamos nos referindo; fornecer instrumentos para organizar mais detalhadamente as sequências e simultaneidades curriculares nas práticas de uso da linguagem (BARBOSA, 2001).

Rojo (2006) afirma que quando se toma os gêneros, e não meramente os textos ou tipos de texto, como objeto de ensino, busca-se constituir um sujeito capaz de inserir-se em atividades de linguagem, as quais envolvem tanto capacidades linguísticas quanto discursivas, relacionadas à apreciação valorativa da situação comunicativa ou contexto, como também capacidades de ação em contexto. Busca-se um outro modo de se produzir e de se compreender textos em sala de aula, onde os alunos são vistos como atores/construtores sociais - no qual o texto passa a ser considerado o próprio lugar da interação e os interlocutores, passam a ser considerados sujeitos ativos.

Tal proposta de organização curricular implica colocar os alunos do ensino médio em contato sistemático com a diversidade textual e de gêneros discursivos. Pois a língua deve entrar na escola da mesma forma que existe vida afora: por meio de práticas sociais de escuta, leitura, escrita e oralidade. Porquanto para formar usuários da língua "é preciso que os alunos ocupem sistematicamente a posição de leitor e escritor para praticar, para construir o hábito, para se sentir embalado pelo prazer de autoria, [...] para se sentir redimido pela imaginação, para poder ser arrebatado pelo conhecimento" (GOUVEIA e ORENSZTEJN, 2006, p. 35).

Deste modo, deve-se tentar ultrapassar, apesar dos limites da escola, a artificialidade que se institui na sala de aula quanto ao uso da linguagem; e possibilitar, pelo uso não artificial da linguagem, o domínio efetivo da língua oral e escrita (GERALDI, 1984). 
No campo da produção textual, é preciso possibilitar aos alunos do ensino médio o acesso e a construção de diferentes produções discursivas, permitindo que - afastados de uma concepção mecânica acerca da linguagem - falem ou escrevam, de fato, algo a alguém. Assim, conforme Geraldi:

Para a produção de qualquer unidade discursiva é necessário considerar que: a) se tenha o que dizer; b) se tenha uma razão para dizer o que se tem a dizer; c) se tenha para quem dizer o que se tem a dizer; d) o locutor se constitua como tal, enquanto sujeito que diz o que diz para quem diz [...]; e) se escolham as estratégias para realizar (a), (b), (c), (d) (GERALDI, 1997, 137).

Enfim, as práticas de produção textual na escola precisam ser socialmente situadas, em contextos de uso ou situações de produção diversificados, nos quais os alunos do ensino médio possam aprender a definir o conteúdo temático, a construção composicional e o estilo verbal a ser utilizado no gênero discursivo vivenciado, adequando-o à situação comunicativa, considerando, entre outros aspectos, qual o objetivo do enunciado, quem é o interlocutor/leitor previsto do texto e quais os efeitos de sentido pretendidos.

Esse outro - o leitor - para quem o texto é pensado e elaborado é, na verdade, a medida para ele que se produz o texto. O outro não se insere apenas na produção de sentidos na leitura do texto, mas já na produção dos enunciados, como condição para que o texto exista. O sentido do texto é já na produção construído a dois (GERALDI, 1997). Portanto, cabe à escola contribuir para que o aluno se aperceba de que o ato da escrita é sempre direcionado ao outro, sendo imprescindível considerar quem é esse sujeito, qual seu lugar social, seu posicionamento ideológico, sua formação, seu grau de instrução e de informação sobre o tema, suas opiniões e suas convicções.

Para efetivar essas práticas de produção textual no ambiente escolar, Silva (2013, p.152-153) sugere como procedimentos didático-metodológicos:

1. Planejamento do texto a ser elaborado conforme as condições de produção para a realização, indicando previamente: o leitor pretendido, os efeitos desejados, o texto e gênero mais adequado à situação. Decidir se a atividade deve ser elaborada de modo individual ou coletivo, incentivando o questionamento e o debate de ideias.

2. Desenvolvimento do texto: assegurar-se de que o aluno conheça bem as características do texto a ser produzido, assim como a definição do gênero mais adequado àquela situação de produção. Fornecer aos alunos outros textos semelhantes, evidenciando as marcas formais que os constituem, para fins comparativos e como apoio à escrita de seu próprio texto. Ainda no que diz respeito ao desenvolvimento, fornecer obras de referência (em papel ou via internet) que possam ser consultadas em caso de dúvidas, 
como gramáticas, dicionários, entre outros materiais de apoio que assegure a pesquisa e a reflexão, especialmente sobre o conteúdo temático a ser abordado no texto.

Em suma, quanto ao desenvolvimento do texto, é preciso oferecer condições de os alunos criarem seus próprios textos e de avaliarem o percurso criador. Isso só se torna possível se os alunos tiverem constituído um amplo repertório de modelos, que lhes permitam criar e recriar as próprias criações. É importante que nunca se perca de vista que não há como criar do nada: é preciso ter boas referências. Assim, formar escritores depende não só de uma prática continuada de produção de textos, mas de uma prática constante de leitura.

3. Aprimoramento da produção textual e reescrita dos textos, pois mesmo o escritor experiente costuma produzir várias versões do texto até chegar ao que julga bem realizado. Esse movimento indica, sobretudo, o complexo processo que envolve a atividade de escrita. Esse momento de revisão da produção textual, na escola, pode representar uma oportunidade singular para a discussão das produções realizadas; troca de ideias em grupos de discussão; a eleição de um dos textos para um estudo mais aprofundado de questões gramaticais, ortografia, adequação do léxico, entre outros elementos relevantes para a produção de sentidos. Os grupos teriam um tempo para examinar os textos, propor mudanças e reescrevê-los, com o objetivo de seu aprimoramento.

Contudo, é preciso que os alunos entendam que reescrever não significa castigo, mas reformulação de um dizer com a finalidade de dizer melhor, ampliando a capacidade de interagir com o leitor de forma criativa. É preciso considerar que nenhum texto se encontra acabado, sendo passível de reformulação e aperfeiçoamento. Sendo assim, certas lacunas deixadas no texto podem ser reelaboradas a partir de provocações propostas pelo professor ou pelos colegas de turma. Nessa dinâmica, novas versões do texto são propostas ao aluno, a partir de problematizações de diversos pontos, favorecendo, assim, o processo de criação textual (CARVALHO, 2011).

Em síntese, a ideia é transformar o espaço da sala de aula do ensino médio numa verdadeira oficina ou ateliê de produção de textos de ação social. Concretizado pela adoção de algumas estratégias, como: enviar uma carta ou e-mail para um parente ou amigo distante; fazer um cartão e ofertar a alguém; encaminhar uma carta de solicitação a um secretário da prefeitura; realizar uma entrevista; elaborar um jornal ou revista para a comunidade escolar, um livro para a biblioteca, um panfleto informativo, um vídeo; organizar uma mesa redonda ou um debate; entre tantas outras possibilidades. O fato de haver uma destinação, divulgação e circulação social incentiva um maior 
envolvimento e compromisso dos alunos. Além disso, é possível inter-relacionar práticas de uso da linguagem com reflexões sobre aspectos formais da língua.

No entanto, a explicitação de informações sobre a estrutura gramatical da língua portuguesa, em qualquer um de seus níveis - fonologia, morfologia, sintaxe e semântica --, só se justifica se facultar ao aluno maior clareza sobre essa estrutura por ocasião do ato de produzir ou ler textos que demandem o uso da língua padrão (RIZZATTI, 2008).

Ou melhor, o ensino de aspectos gramaticais da língua materna - como, por exemplo, as classes de palavras, a análise sintática, a conjugação verbal, a regência verbal e nominal - não se legitima por outro motivo que não a possibilidade de os alunos transporem esses conhecimentos no momento em que estiverem vivenciando práticas de produção e leitura de textos, não apenas na escola, mas nas demais dinâmicas comunicativas. Deste modo, em nada adianta trabalhar questões estruturais da língua se o aluno não for capaz de acionar esses conhecimentos no momento em que for ler e produzir textos.

O aluno precisa saber quando e como usar esses aspectos formais da língua e, para tanto, esse conteúdo precisa ser ensinado inserido em contextos reais de uso da língua. Deste modo, é conveniente que o ensino dos fatos gramaticais da língua materna e o ensino de produção e leitura textuais possam ser arrolados como experiências curriculares articuladas e interligadas. De modo que o ensino da língua materna parta sempre do texto e possa - a partir daí - adentrar a análise de suas unidades constituintes, mas vislumbrando sempre retornar ao texto - à unidade de sentido.

No ensino da língua materna, sob essa perspectiva social e discursiva, a avaliação das produções textuais abandona os critérios quase que exclusivamente literários ou gramaticais e desloca seu foco para outro ponto: o bom texto é aquele que é adequado à situação comunicacional para a qual foi produzido, ou seja, se a escolha do gênero, se a estrutura, o conteúdo, o estilo e o nível de língua estão adequados ao interlocutor e podem cumprir a finalidade do texto.

No campo da leitura, do mesmo modo como nas práticas de produção textual, o processo de ensino e aprendizagem da língua materna no ensino médio, deve buscar uma participação ativa dos alunos. É necessário considerar que, assim como o escritor precisa assumir uma posição de autoria de seus textos, o leitor não é passivo, mas agente que busca significações. Ele se aproxima do texto com perguntas, cujas respostas, sempre provisórias, atualizam e revivificam o texto lido. Em outras palavras, o leitor se figura como coautor ao atualizar as perguntas e respostas, também provisórias, que o escritor tinha em mente ao produzir seu texto. 
Assim, enquanto o produtor do gênero tem, por seu lado, um projeto de dizer, o leitor, por outro, deve buscar os sentidos e a significação do texto por meio da mobilização do contexto, bem como de pistas que o próprio texto apresenta. O contexto, segundo Koch (2003), engloba:

a) Co-texto - material verbal que compõe o texto;

b) Situação de interação imediata;

c) Situação de interação mais ampla que reflete questões sociais, políticas e culturais;

d) Contexto cognitivo - todo tipo de conhecimento mobilizado tanto pelo produtor como pelo leitor do texto: o conhecimento linguístico, o conhecimento de mundo, o conhecimento da situação comunicativa, o conhecimento de gêneros discursivos e, também, o conhecimento de outros textos que permeiam a nossa cultura, envolvendo a intertextualidade.

Assim sendo, o sentido do texto não está dado a priori, mas se constrói na interação estabelecida entre o próprio texto e os sujeitos, evidenciando o dinamismo implicado na leitura em que necessariamente se estabelece uma relação entre leitor e autor - sujeitos sociais - em um processo de interlocução (MACHADO, 2007).

Como os sujeitos são distintos e suas experiências, conhecimentos, valores e lugares sociais diversos, haverá sempre uma pluralidade de leituras e de sentidos em relação a um mesmo texto. No entanto, o leitor não está livre para dar o sentido que bem quiser a um texto. O sentido do texto não está apenas no leitor, nem no texto, mas na interação autor-texto-leitor. É preciso considerar as pistas e sinalizações do texto, bem como o contexto.

Considerando tais aspectos, o enfoque metodológico da leitura no ensino médio, para que, de fato, contribua para o processo de formação de leitores, não deve se deter simplesmente em atividades de localização de informações e a paráfrase, é preciso propor a exploração da intertextualidade, da interdiscursividade, da interdisciplinaridade, dos recursos linguísticos, dos recursos estilístico-estéticos e de estratégias diversificadas, como, por exemplo, a antecipação, a predição, o levantamento e checagem de hipóteses, a elaboração de inferências, comparação e generalização de informações, o levantamento de questionamentos, entre outras, a formação de juízos próprios com respostas de caráter subjetivo (MARTINS, 2006).

Neste ponto, é essencial que os alunos se conscientizem da existência, em cada texto, de diversos níveis de significação. Além da significação explícita, existe toda uma gama de significações implícitas, muito mais sutis e diretamente ligadas à intencionalidade do autor (subentendidos, inferências, pressupostos). Como assinala os PCNEM (BRASIL, 2000b), formar 
um leitor competente supõe formar alguém que compreenda o que lê, que possa aprender a ler também o que não está escrito.

Enfim, o importante é que a orientação leitora ultrapasse a decifração do material linguístico e o nível da construção do significado na estrutura das orações, de modo que o ensino da leitura possibilite ao aluno desenvolver diferentes níveis de compreensão leitora, constatar como se desenvolve sua comunicação com o texto e refletir sobre o que dela resulta. Para tanto, é necessária uma participação ativa do aluno enquanto leitor.

Assim, nas práticas de leitura em sala de aula, a interação entre aluno e professor e a interação entre alunos são primordiais, dado que em tais interações emerge, não raro, a construção efetiva dos sentidos do texto. A experiência dos leitores é crucial e precisa ser requerida no ato de ler. Essa postura ativa, no entanto, não legitima suplantar a voz do autor (KLEIMAN, 2001; KOCH, 2003).

A questão que se coloca é como elaborar essas práticas em sala de aula sem cair num processo de simulação de leituras. Entende-se que o primeiro passo seria utilizar os portadores originais de textos e explorar os elementos que compõem o gênero discursivo em questão.

Assim sendo, o trabalho com leitura não pode ser feito através de fragmentos de textos trazidos nos livros didáticos, o que os torna pseudotextos, às vezes começando pela metade, outras vezes com seu final alterado ou ignorado, ainda outras com recortes feitos no corpo do texto apenas para adequá-lo ao espaço do livro didático. Daí a importância de se buscar, no ensino médio, uma relação discursiva com os portadores originais dos textos que transcenda as limitações e inadequações de algumas abordagens escolares dos gêneros discursivos. Esses portadores originais de textos possibilitam aos alunos aperceberem-se não apenas da estrutura formal do discurso e de seu estilo verbal, mas também de seu conteúdo temático e do contexto de uso ou situação de produção do enunciado em questão.

Deste modo, se se pretende formar leitores e escritores no ensino médio é preciso fazer parte do universo escolar não apenas os livros didáticos, mas também os portadores originais do texto, obras integrais de literatura - os clássicos e os contemporâneos -, os jornais, as revistas, os folhetos, os hipertextos, enfim os mais variados tipos de textos, suportes e gêneros. Do mesmo modo, é necessário que tais práticas envolvam os mais variados contextos de leitura: em sala de aula, em bibliotecas ou em outros espaços culturais.

Assim, outro aspecto didático-metodológico relacionado ao ensino da língua materna, diz respeito a escolha dos livros a serem oferecidos aos alunos do ensino médio em sala de aula. 
Segundo Borba (2006), esta escolha deve ser cuidadosa, uma vez que não existe obra cultural inocente, todas elas estão impregnadas de uma visão de mundo - a do autor. Para que o aluno não fique enredado na concepção de mundo dos outros, e nem seja por ela manipulado, é preciso que se desenvolva uma leitura crítica que leve o aluno a pensar, a questionar, a interrogar, a atribuir sentidos, enfim, a se constituir como leitor.

Para tanto é necessário que a escola promova leituras com abordagens, temáticas e opiniões variadas, possibilitando aos alunos o diálogo com uma grande diversidade de livros e de culturas, com visões de mundo diferentes umas das outras, de modo que a leitura de um texto dialogue permanentemente com a dos outros.

A respeito da premência de se instituir como conteúdo curricular do ensino da língua materna a diversidade de culturas, há que se considerar que as salas de aula são povoadas pela heterogeneidade linguística associada aos diferentes perfis sociais e culturais dos alunados. De modo que se faz necessário empreender uma prática pedagógica que leve em conta a pluralidade de realizações empíricas da língua (BAGNO, 2002). O que implica afirmar que é imperativo trazer para o centro do ensino da língua materna a diversidade linguística. A discussão sobre essa variedade é essencial para que os alunos não criem ou alimentem preconceitos em relação aos falares diversos que compõem o espectro do português utilizado no Brasil.

O professor pode valer-se de estudos da Sociolinguística para expor a seus alunos que as variedades faladas pelos diferentes sujeitos são perfeitamente adequadas ao pensamento lógico e à aprendizagem e que a distinção inferioridade/superioridade constitui um fenômeno social e político (BAGNO, 2002; GREGOLIN, 2007).

Deste modo,

[...] uma das tarefas do ensino de língua na escola seria, portanto, discutir criticamente os valores sociais atribuídos a cada variante linguística, chamando a atenção para a carga de discriminação que pesa sobre determinados usos da língua, de modo a conscientizar o aluno de que sua produção linguística, oral ou escrita, estará sempre sujeita a uma avaliação social, positiva ou negativa (BAGNO, 2006, p, 8).

Associado a isto, Bagno (2002) sinaliza que o ensino da língua na escola brasileira tem visado, tradicionalmente, reformar ou consertar a língua do aluno, considerado, logo de saída, como um deficiente linguístico. Esse modo de conceber os fatos de linguagem condena ao submundo do não ser todas as manifestações linguísticas não normativas, rotuladas automaticamente como erros. E, junto com as formas linguísticas estigmatizadas, condena-se ao silêncio e à quase-inexistência as pessoas que se servem delas. 
Ao contrário disso, cabe à escola reconhecer a legitimidade da variedade linguística utilizada por seus alunos, a ponto de trabalhar com ela em sala de aula, reconhecendo que tal língua vale para seus fins, tanto quanto a variedade padrão vale para outros fins. Isso porque, segundo Cyranka e Pernambuco(2008), enquanto a escola insistir em negar o caráter sócio-histórico-funcional dessa variedade, ela ao invés de aproximar os alunos da língua padrão, os distancia da crença de que são capazes de adquirir a competência de uso dessa variedade mais prestigiada e diferente da que utilizam.

Os PCNEM (BRASIL, 2000a) indicam que os alunos conheçam as várias manifestações como produto de diferentes esferas sociais. Em lugar de criar fossos entre as manifestações, sugerem que se criem elos entre elas. A língua padrão pode ser comparada com as outras variantes em seus aspectos fonológicos, sintáticos, semânticos. "O exame da complexidade das manifestações evoca a superação preconceituosa das identidades e provoca o respeito mútuo como meio de entender o presente e construir o devir" (BRASIL, 2000a, p. 10).

A organização curricular do ensino da língua materna para o ensino médio deve, portanto, ser pensada e praticada de tal modo que todos possam aprender e ter acesso a língua socialmente prestigiada, enriquecendo seu repertório linguístico, sem que isso implique a desvalorização de sua própria variedade linguística, adquirida nas relações sociais dentro de sua comunidade (BORTONIRICARDO, 2004).

Assim, cabe a escola ensinar a língua padrão, considerando sua utilização social, mas ter atitudes positivas e não discriminatórias em relação às variedades linguísticas de seus alunos. É preciso garantir ao aluno o direito de optar por uma determinada variante, conforme a situação de uso, sem que seja discriminado por isso.

Também é essencial que a escola apresente aos alunos as diferentes formas proferidas por pessoas de diversas regiões, de diversos estratos sociais, de diversas faixas etárias, etc. A fim de conscientizar os alunos de que a sua forma de falar é tão valiosa como a norma padrão ensinada na escola.

Portanto, a abordagem das variações da língua incorpora-se à organização curricular do ensino da língua materna não apenas para esclarecer aos alunos que existem variedades linguísticas que identificam geográfica e socialmente as pessoas e sobre os preconceitos decorrentes do valor social que é atribuído aos diferentes modos de fala e de escrita. Cabe ainda oferecer situações de aprendizagem que possibilitem aos alunos utilizarem as diversas variedades linguísticas de sua língua, que lhes permitam conquistar as condições de participação cultural, social e política. 
Enfim, insere-se ao programa de ensino da língua materna uma prática de construção, de compreensão e de reflexão sobre os usos das variedades em diversos contextos, isso porque é importante para os alunos adequarem a sua linguagem a cada situação de comunicação.

\section{CONSIDERAÇÕES FINAIS}

Assim conclui-se que, na perspectiva acima esboçada, o ensino da língua materna no ensino médio tem por finalidade contribuir para que os alunos assumam: - uma posição de autores de seus discursos, capazes de mobilizarem seus interlocutores na construção do sentido do seu texto; - uma posição de leitores do discurso do outro, atribuindo conceitos ao que lê e buscando sua significação. Trata-se da construção de uma competência discursiva por parte dos alunos e para tanto, é preciso que a escola ultrapasse os limites estreitos de suas práticas exclusivamente escolares e propicie práticas letradas que envolvam gêneros específicos que se configurem em textos específicos textos em gêneros de circulação social concreta - os quais são importantes para a prática social ativa e cidadã dos alunos.

Propõe-se, assim, uma organização curricular em que o ensino da língua materna se dê a partir de um modo diferenciado de produzir e de compreender textos em sala de aula, em que haja uma continuidade da apropriação de práticas sociais em circulação em espaços públicos e formais. Nesse entendimento, o ensino dos fatos gramaticais da língua materna e o ensino de produção e leitura textuais são arrolados como complementares e indissociáveis. A expectativa é formar alunos que sejam capazes de produzir e compreender textos de uso social - orais e escritos - a fim de que tenham trânsito livre nas várias situações comunicativas que permitam plena participação no mundo letrado. Trata-se, portanto, da tarefa de contribuir para a formação de sujeitos capazes de responder a diferentes exigências comunicativas que envolvam as diferentes linguagens.

\section{REFERÊNCIAS}

BAGNO, M. Nada na língua é por acaso: Ciência e senso comum na Educação em Língua Materna. Ciência Pedagógica, Belo Horizonte, ano 12, n.71, set. 2006.

BAGNO, M. A inevitável travessia: da prescrição gramatical à educação linguística. In: BAGNO, M; STUBBS, M; GAGNÉ, G. Língua Materna: letramento, variação e ensino. São Paulo: Parábola Editorial, 2002.

BAKHTIN, M. Estética da Criação Verbal. 2. ed. São Paulo: Martins Fontes, 1997.

BARBOSA, J.P. Do professor suposto pelos PCNs ao professor real de Língua Portuguesa: seriam os PCN praticáveis? In: ROJO, R. H. R. (Org.). A prática de linguagem em sala de aula: praticando os PCN. Campinas: Mercado de Letras, 2001. p. 149-182.

BORBA, M. Literatura e pluralidade cultural. In: CARVALHO, M.A.F.; MENDONÇA, R.H. (Orgs.). Práticas de leitura e escrita. Brasília: Ministério da Educação, 2006, p.108-111. Disp.: <http://tvescola.mec.gov.br>. Acesso: 16 fev. 2015. 
BORTONI-RICARDO, S.M. Educação em Língua Materna: a sociolinguística em sala de aula. São Paulo: Parábola, 2004.

BRASIL. MEC/SEMT/CGEM. Parâmetros Curriculares do Ensino Médio: Linguagens, Códigos e suas Tecnologias. Brasília: MEC/SEMT, 2000a.

MEC/. PCN Ensino Médio + Orientações Educacionais Complementares aos Parâmetros Curriculares Nacionais: Linguagens, Códigos e suas Tecnologias. Brasília: MEC/SEMT, 2000b.

CARVALHO, J. R. Criatividade no processo de produção textual: imaginação, mediação e interações. In: SAMPAIO, C.S.; PÉREZ, C.L.V. (Coords.). Alfabetização e Letramento: O que muda quando muda o nome? Rio de Janeiro: Editora Rovelle, 2011, p. 227-241.

CARVALHO, M.A.F.; MENDONÇA, R.H. Apresentação. In: (Org.). Práticas de leitura e escrita. Brasília: Ministério da Educação, 2006, p.8-9. Disponível em: 〈http://tvescola.mec.gov.br. Acesso em: 16 fev. 2015>.

CYRANKA, L.F.M; PERNAMBUCO, D.L.C. A língua culta na escola: uma interpretação sociolinguística. Instrumento: Revista de Estudo e pesquisa em Educação, Juiz de Fora, v. 10, p.17-28, jan./dez. 2008.

FIORIN, J.L. Introdução ao pensamento de Bakhtin. São Paulo: Ática, 2008.

GERALDI, J. W. Portos de passagem. São Paulo: Martins Fontes, 1997.

GERALDI, J. W. Prática de leitura de textos na escola. Leitura: Teoria e Prática, Campinas, ano 3, n. 3, p. 25-32, Jul. 1984.

GOUVEIA, B.; ORENSZTEJN, M. Alfabetizar em contextos de letramento. In: CARVALHO, M.A.F.; MENDONÇA, R.H. (Org.). Práticas de leitura e escrita. Brasília: Ministério da Educação, 2006, p.34-37. Disponível em: http://tvescola.mec.gov.br. Acesso em: 16 fev. 2015.

GREGOLIN, M.R. O que quer, o que pode esta língua? Teorias linguísticas, ensino de língua e relevância social. In: FARACO, C.A.; CORREIA, D.A. (Org.). A relevância social da linguagem: linguagem, teoria e ensino. São Paulo: Parábola Editorial; Ponta Grossa, PR: UEPG, 2007.

KLEIMAN, A. Oficina de Leitura. 2 ed. São Paulo: Pontes, 2001.

KOCH, I. G. V. Desvendando os segredos do texto. 2 ed. São Paulo: Cortez, 2003.

MACHADO, M.L.C.A. A escrita alfabética, sua natureza e representação: contribuições à Fonoaudiologia aplicada à Educação. 2013. 157f. Tese (Doutorado em Educação) - Faculdade de Educação, Universidade do Estado do Rio de Janeiro, Rio de Janeiro, 2013.

MACHADO, M.L.C.A. Grupo de linguagem escrita: uma proposta de intervenção fonoaudiológica. 2007. 173f. Dissertação (Mestrado em Distúrbios da Comunicação Humana) - Universidade Tuiuti do Paraná, Curitiba, 2007.

MARCUSCHI, L.A. Gêneros Textuais: definição e funcionalidade. In: DIONISIO, A.P.; MACHADO, A.R.; BEZERRA, M.A. (Orgs.). Gêneros textuais \& Ensino. São Paulo: Parábola Editorial, 2010. p. 19-36.

MARTINS, A.A A leitura literária nos livros didáticos. In: CARVALHO, M.A.F.; MENDONÇA, R.H. (Org.). Práticas de leitura e escrita. Brasília: Ministério da Educação, 2006, p. 116-119. Disp.: http://tvescola.mec.gov.br. Acesso em: 16 fev. 2015.

RIZZATTI, M. E. C. Implicações metodológicas do processo de formação do leitor e do escritor de textos na escola. Educação em Revista, Belo Horizonte, n. 47, p.1-15, junho. 2008.

ROJO, R. Letramento e diversidade textual. In: CARVALHO, M.A.F.; MENDONÇA, R.H. (Org.). Práticas de leitura e escrita. Brasília: Ministério da Educação, 2006, p.24-29. Disp.: http://tvescola.mec.gov.br. Acesso em: 16 fev. 2015.

ROJO, R.; BARBOSA, J.P. Hipermodernidade, multiletramentos e gêneros discursivos. São Paulo: Parábola Editorial, 2015.

SENNA, L.A.G. Psicolinguística e sistemas gramaticais no campo da psicopedagogia. In: GODOY, E.; SENNA, L. A. Psicolinguística e Letramento. Curitiba: Editora IBPEX, 2011. p. 129- 194.

SILVA, M.C. O texto como aliado do trabalho do professor das séries iniciais do Ensino Fundamental. In: Leitura, pesquisa e ensino. Rio de Janeiro: EdUERJ, 2013, p. 143-156. 


\section{RESUMO}

Este artigo problematiza as finalidades e a organização curricular do ensino de língua materna no Ensino Médio, a partir de um estudo de natureza teórico-conceitual. Os resultados apontam que o ensino de língua materna tem como finalidades desenvolver no aluno seu potencial crítico, sua percepção das múltiplas possibilidades de expressão linguística, sua formação como leitor e escritor efetivo dos mais diversos textos representativos de nossa cultura. Para tanto, faz-se necessário uma organização curricular em que o ensino dos fatos gramaticais e de produção e leitura textuais sejam arrolados como experiências articuladas e interligadas. Conclui-se que é necessário que a escola propicie aos alunos um contato sistemático com textos, os quais são essenciais para a prática social ativa.

Palavras-chave: Linguagem; Texto; Ensino Médio.

\section{THE NATIVE LANGUAGE IN HIGH SCHOOL: Purposes and curricular organization}

\section{SUMMARY}

This article discusses the purposes and the curricular organization of native language teaching in High School, based on a theoretical-conceptual study. The results point out that the teaching of native language intends to develop in the student his critical potential, his perception of the multiple possibilities of linguistic expression, his formation as a reader and effective writer of the most diverse texts representative of our culture. Therefore, it is necessary a curricular organization in which the teaching of grammatical facts and that of textual production and reading be considered as articulated and interconnected experiences. We conclude that it is necessary that the school provide students with a systematic contact with texts, which are essential for active social practice.

Keywords: Language; Text; High school. 